\title{
Developing and Sustaining a Web-Based Library Newsletter
}

\section{JESENEm}

ABSTRACT

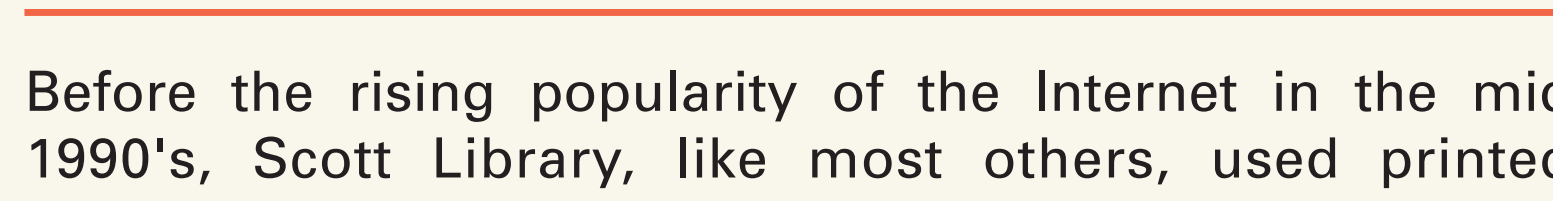

hensleters to intiorm Hsers about new resources and

the Librarr's newsiterter by emploving the technicic

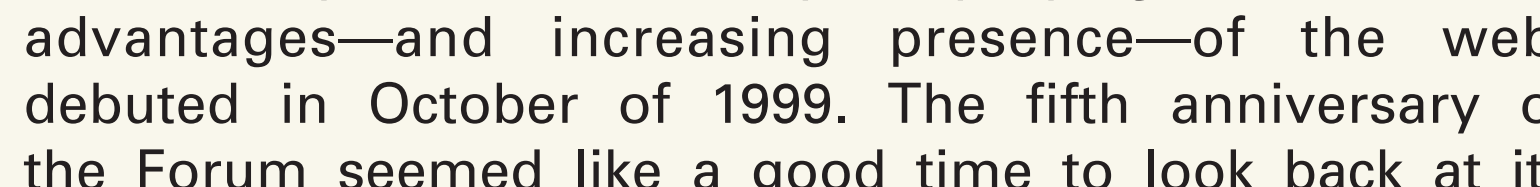

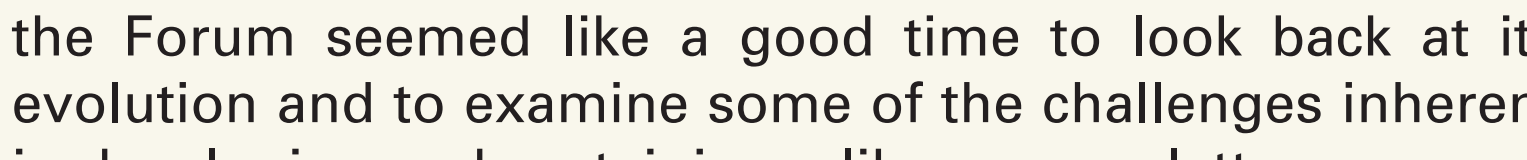

BACKGROUND AND HISTORY

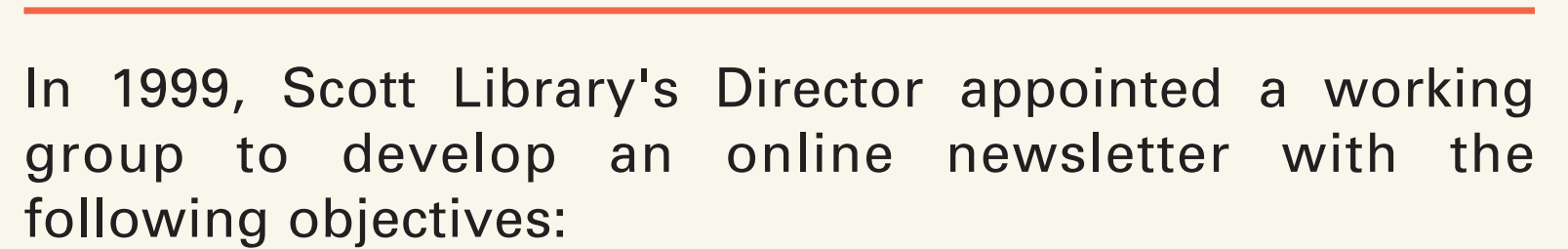
following objectives:

Develop content to highight and support:
- Librar news and information (primar focus)

"Educational nititatuves and acturtes involing the

participation of Library and AlSh staff members
(secondary focus)

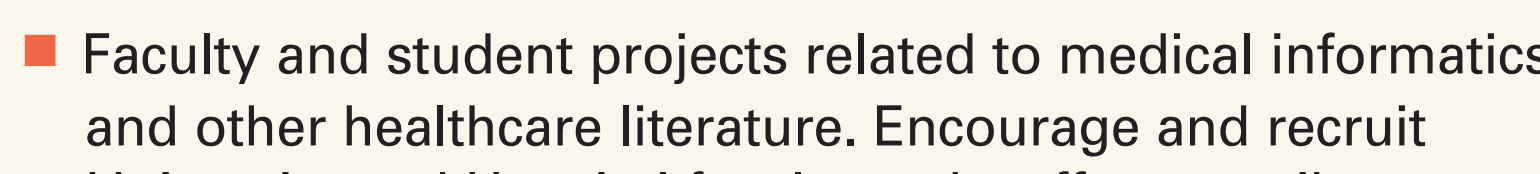

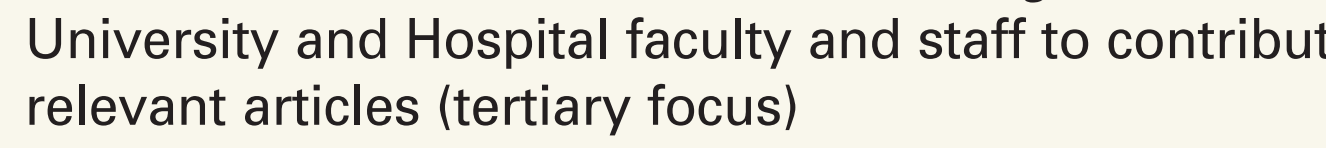

Implement these features for the site:

- Archive of previous issues

A Ability to search content tinduding current issue
and

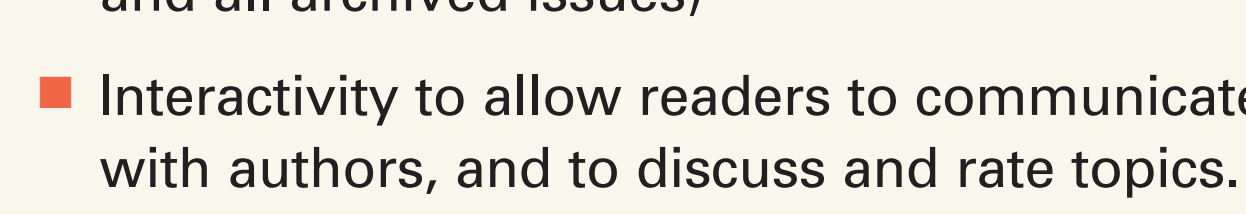

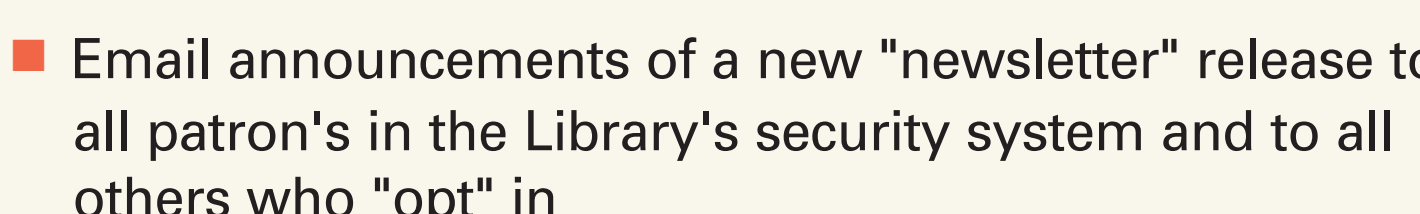

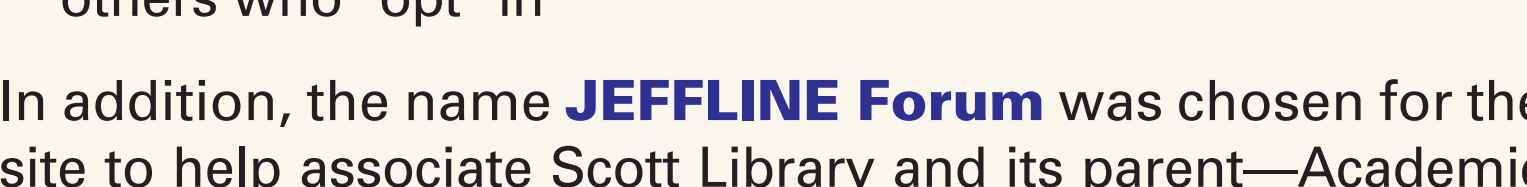

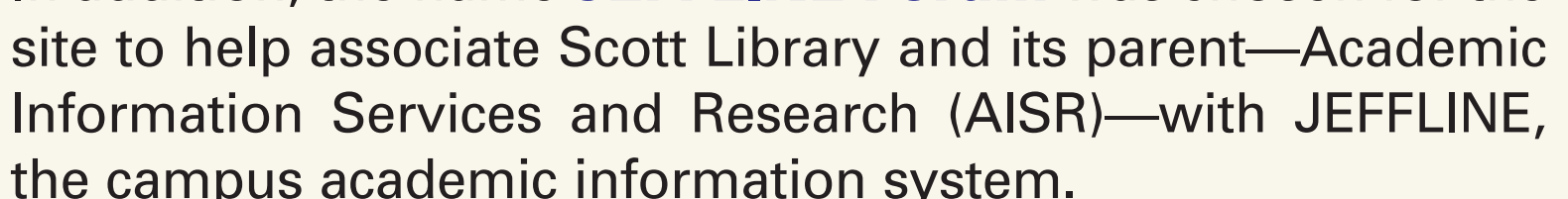

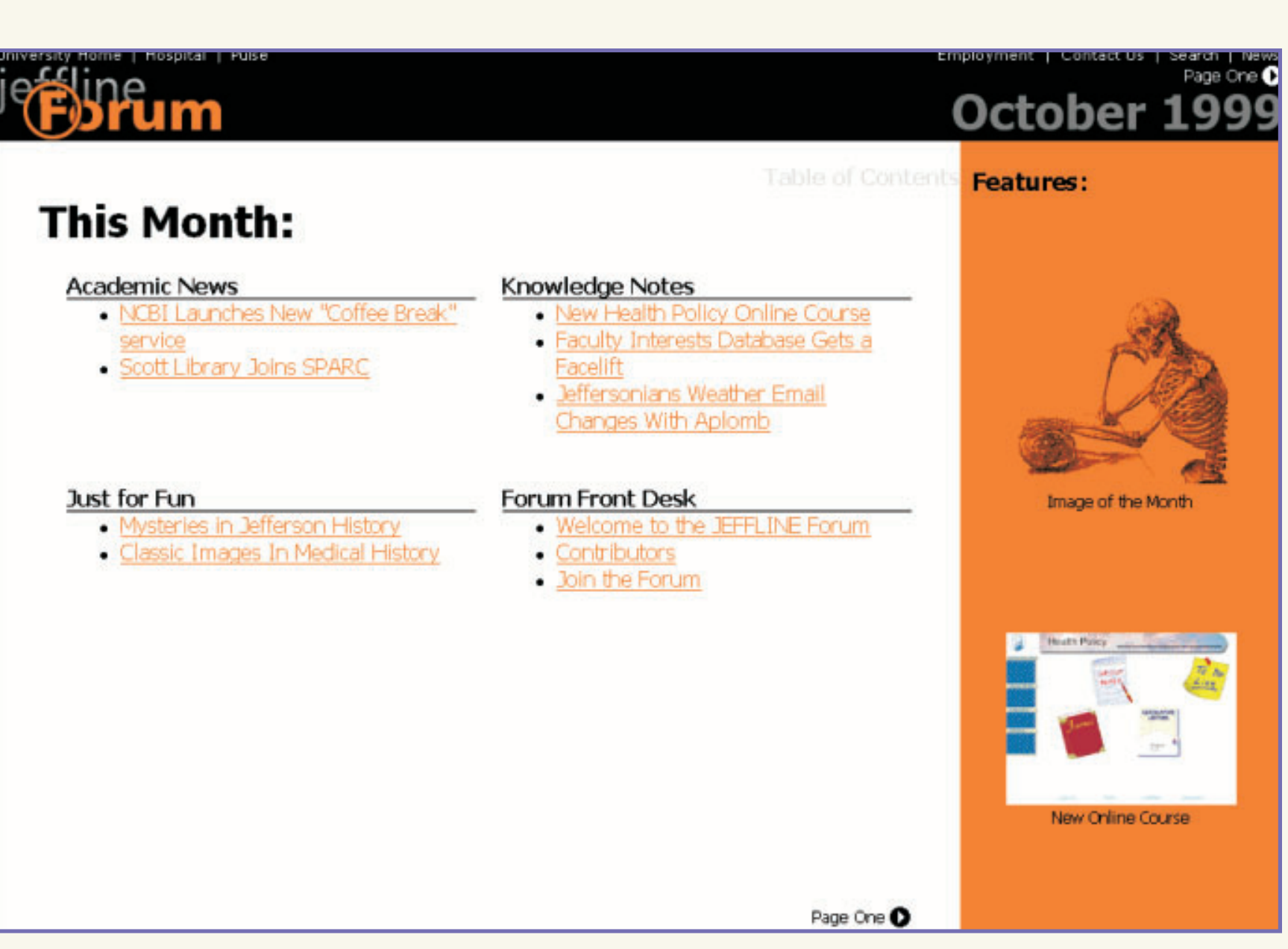

The first issue of the JEFFLINE Forum, October 1999 contents page containing links to articles and at least on

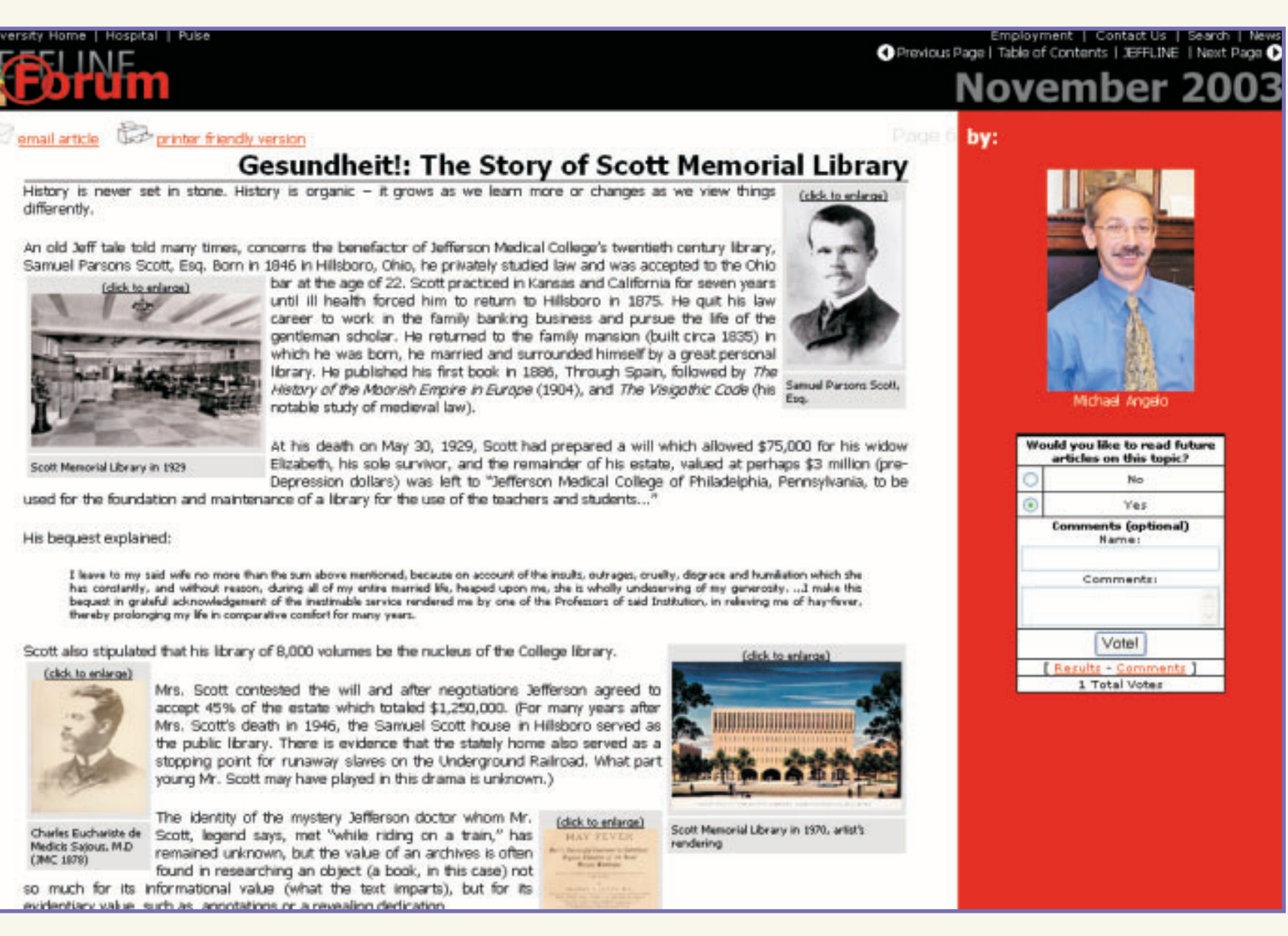

From the beginning the Forum has highlighted the rich collection of objects and images in our University Archives These have been among the most frequently read articles

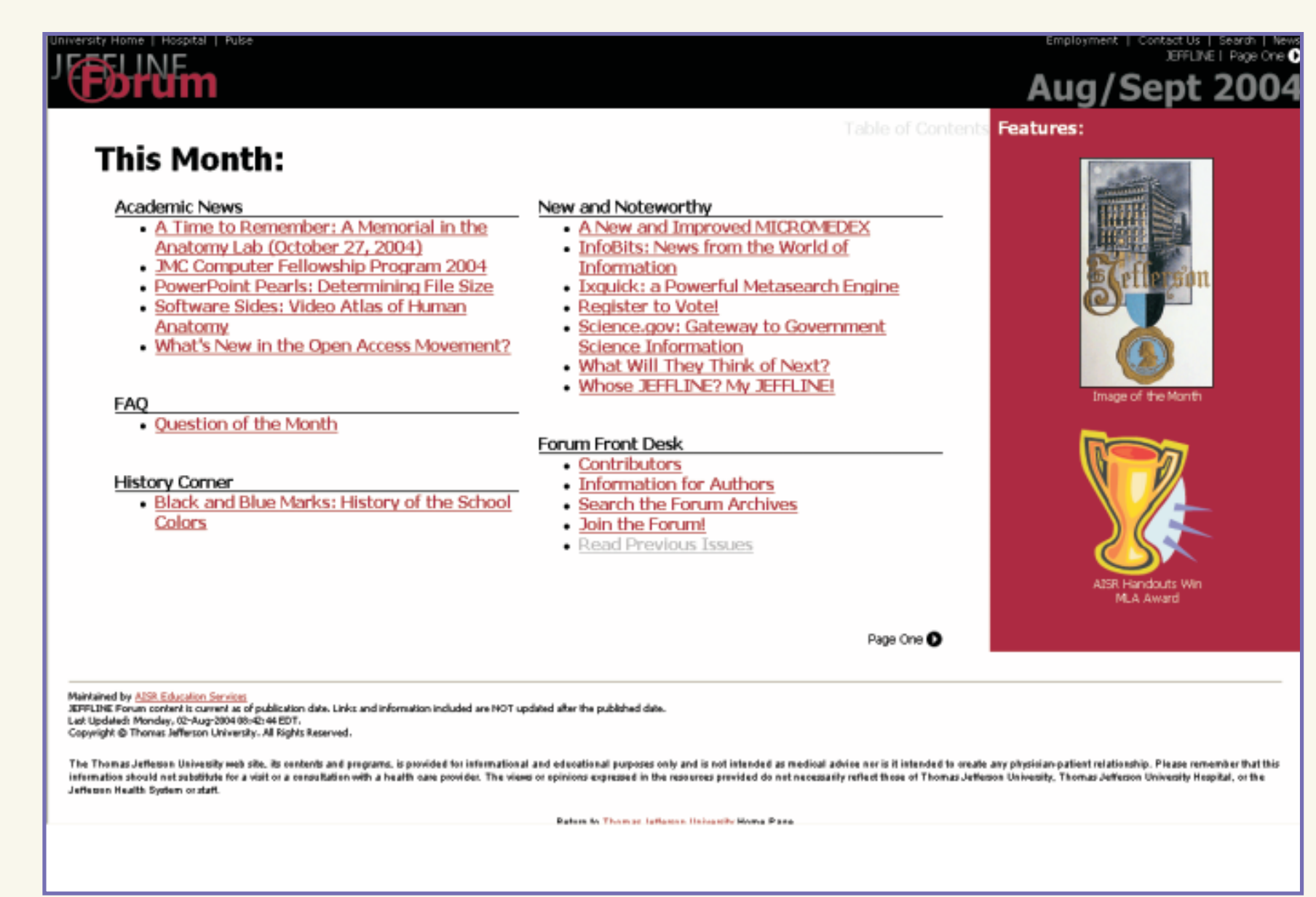

The same basic design is still used today,
hut The The current issue is available at: hitp://ieffline jefferson. edu/Education/forum/

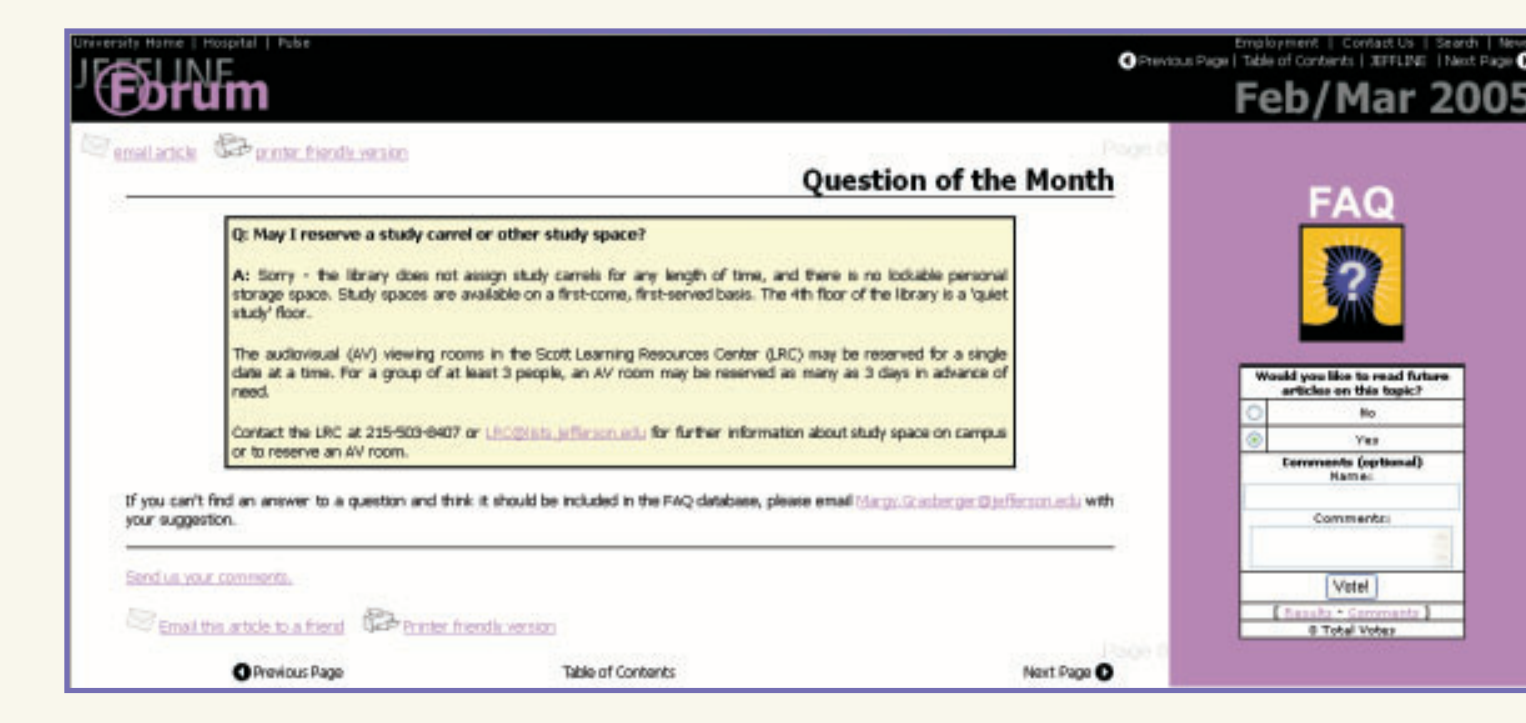

Regular features like Question of the Month (above)
and InfoBits bl below) have been added over time.

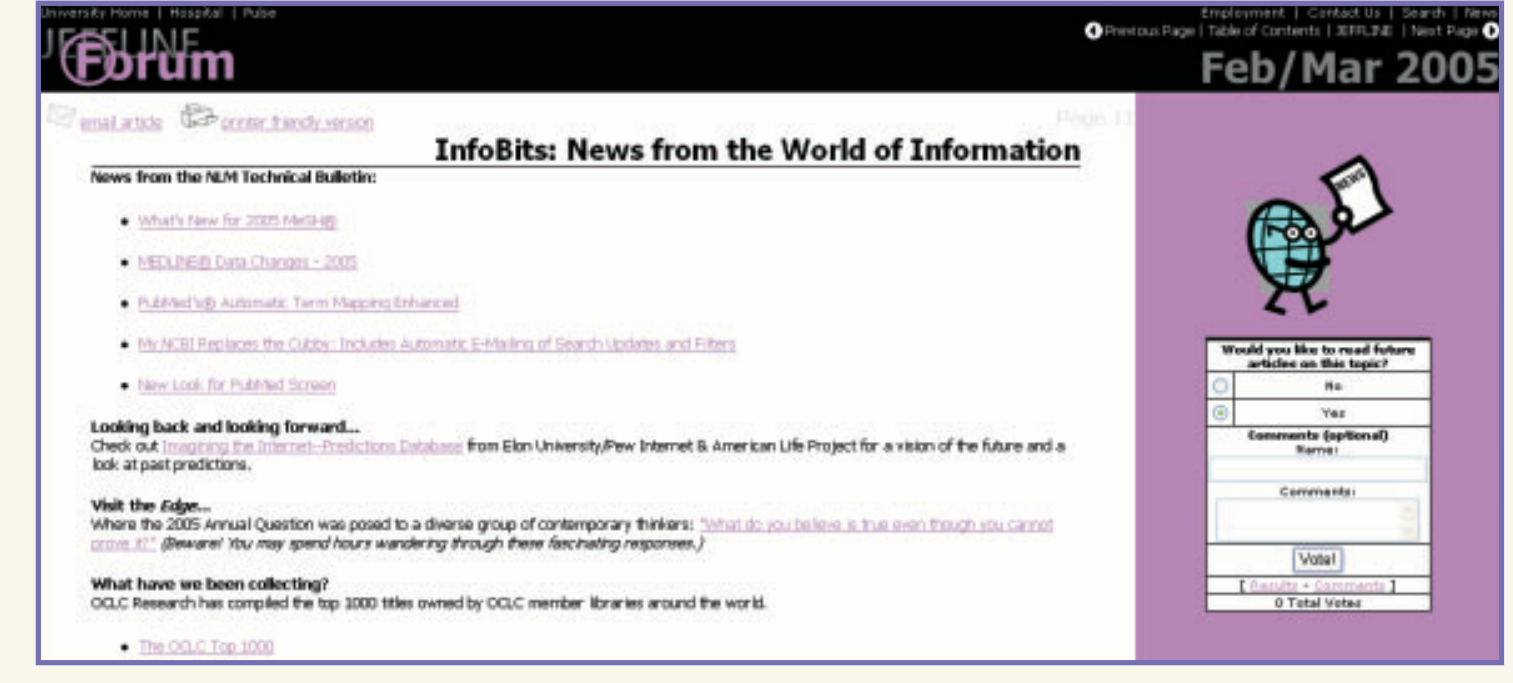

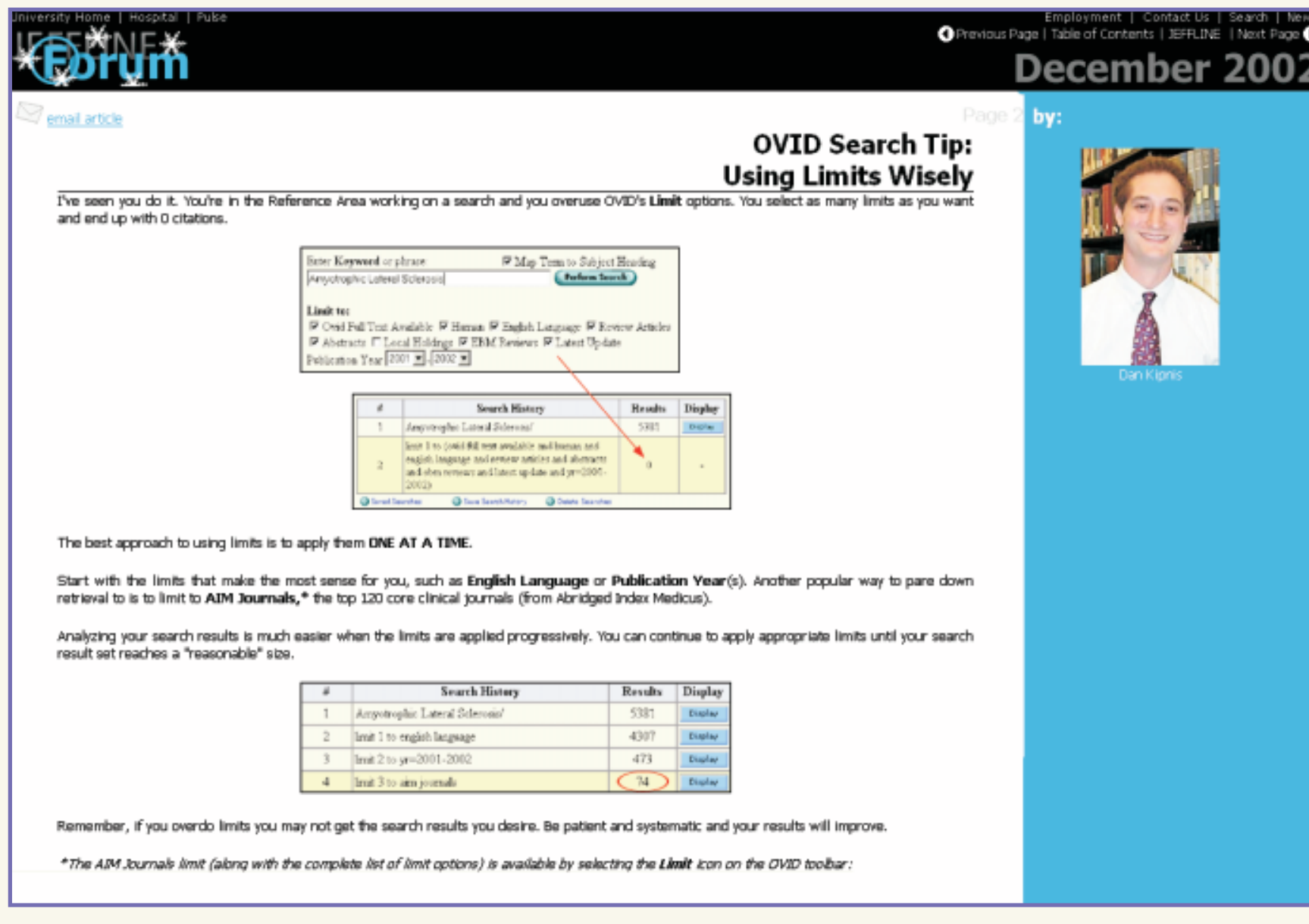

The Forum regularly offers searching tips focusing on a specific
feature of a resource such as Ovid, PubMed, or Google.

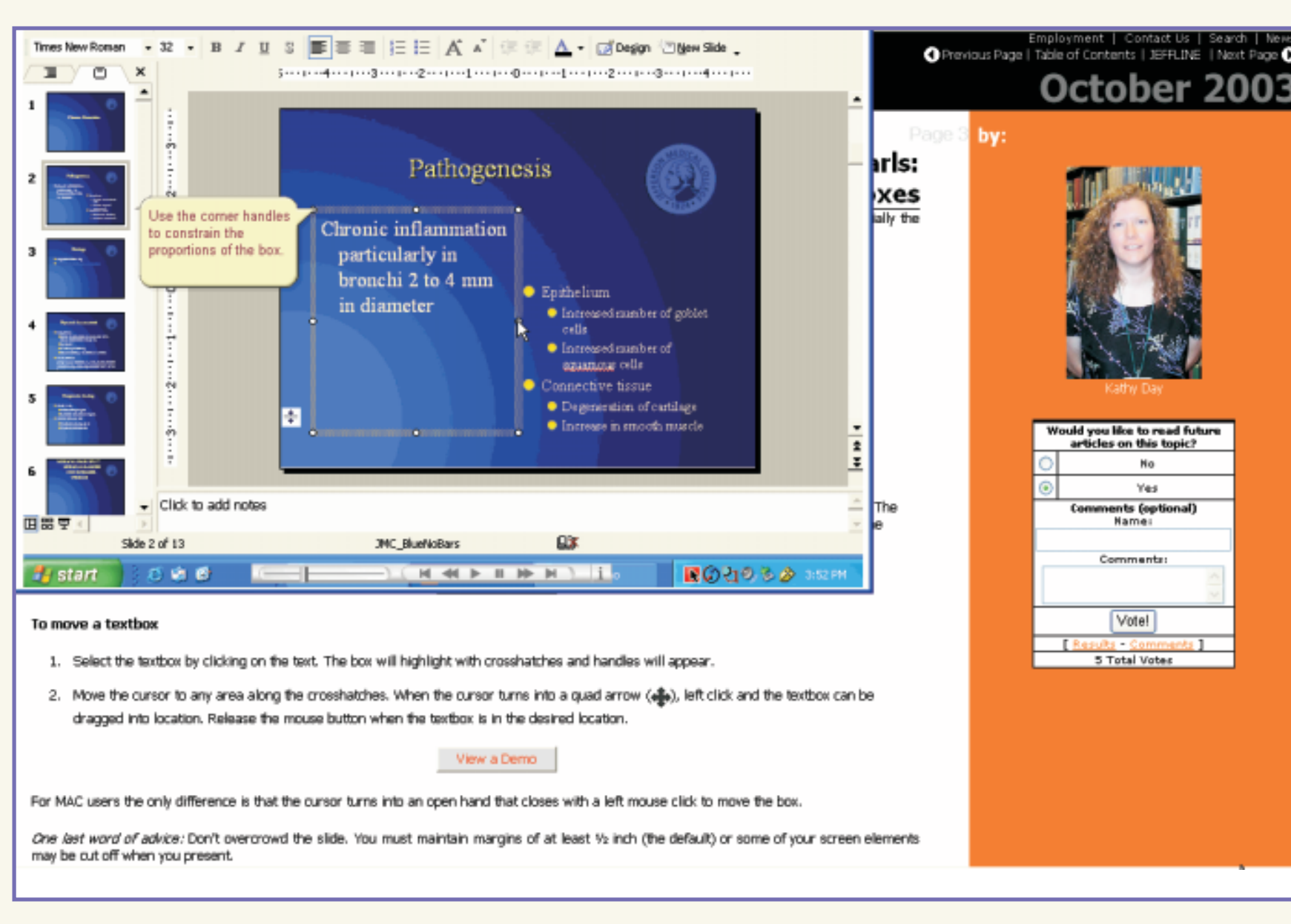

Clicking View a Demo launches a separate window containing an automated demonstratition of the tip or
technique discussed in the article. (Flash movie)
ABSTRACT

Challenges:

est in participation

Recruiting "outside" authors

- Incorporating technology

Successful Strategies:

Establishing ties with library staff to contribute

New Books, Powerpoint Tips, Search Tips, InfoBits,

Creating automated demos
"how to" articles and "tips."

Adding a printer-friendly link and email article

Experience and Lessons Learned:

It can be difficult to recruit new authors. Tap campus
connections and workshop attendees as potential

contributors

"Tracking reader's interests is tricky. We use IMDpoll
ffrewarer for online polll, but receive relatively few
responses

- Readers like the flash demos created using Camtasia and
Robodemo which are incorporated into some articles. We recognize that the Forum is time consuming to
edit and assemble-approximately 25 hours per issue edit and assemble-approximately 25 hours per iss
(not including writing time)-even with increased
experience and efficiency As of February 2005 , over 1,500 Jeffersonians and
non- leffersonians subscribe to the JEFFLINE Forum 